\title{
On how CCN6 suppresses breast cancer growth and invasion
}

\author{
Wei Huang • Anupama Pal · Celina G. Kleer
}

Received: 3 August 2011 / Accepted: 4 August 2011 / Published online: 13 August 2011

(C) The Author(s) 2011. This article is published with open access at Springerlink.com

\begin{abstract}
Living cells communicate with their microenvironment and exchange information through signaling pathways in order to carry out most biological processes. The CCN family of proteins has the ability to coordinate the extracellular and intracellular signaling pathways and epithelial-stromal cross-talks. CCN proteins have been shown to play roles in multiple processes including cancer, either as tumor suppressors or oncogenes. Particularly, loss of CCN6 expression has been reported in highly aggressive breast cancer types, especially in inflammatory breast cancer and breast cancer with axillary lymph node metastasis. Recent findings can better explain the biological relevance of $\mathrm{CCN} 6$ as a tumor suppressor protein in breast tumorigenesis. CCN6 loss triggers the process of epithelial to mesenchymal transition (EMT), which converts epithelial cells into migratory and invasive mesenchymal-like cells at least in part through modulation of IGF-1 receptor signaling pathway. Emerging data support the hypothesis that $\mathrm{CCN} 6$ also exerts growth factor independent functions, especially related to cell survival and anoikis resistance. Thus, our work provides new insights into the functions and mechanisms of tumor suppression exerted by CCN6 in the breast.
\end{abstract}

Keywords Epithelial to mesenchymal transition - $\mathrm{CCN} 6$. WISP3 - Insulin like growth factor - Breast cancer .

Inflammatory breast cancer

Wei Huang and Anupama Pal contributed equally

W. Huang $\cdot$ A. Pal $\cdot$ C. G. Kleer $(\bowtie)$

Department of Pathology and 4217 Comprehensive Cancer

Center, University of Michigan Medical School,

1500 E. Medical Center Drive,

Ann Arbor, MI 48109, USA

e-mail: kleer@umich.edu

\section{Introduction}

Invasive carcinomas of the breast are largely adenocarcinomas characterized by invasion of adjacent tissues and propensity to metastasize. The discovery of strategies to halt or prevent invasion and metastasis are needed to improve clinical outcome. Invasive carcinomas are embedded in a desmoplastic stroma containing fibroblasts, myofibroblasts, immune system cells, structural proteins, and vessels. It has become clear in recent years that microenvironmental signals exert a powerful influence on the behavior of epithelial cells. Given their ability to regulate extracellular signaling, the $\mathrm{CCN}$ proteins have the potential to impact the response of cancer cells to the extracellular stimuli.

CCN6 protein was found to have tumor growth and invasion inhibitory functions in inflammatory breast cancer and aggressive non-inflammatory breast cancer (Huang et al. 2008; Huang et al. 2010; Kleer et al. 2002). Inflammatory breast cancer (IBC) is the most lethal form of locally advanced breast cancer. It is rare, accounting for $1-5 \%$ of all breast cancers in the United States (Dawood and Cristofanilli 2007; Ventura and Merajver 2008). IBC carries a significantly worse prognosis than non-inflammatory breast cancers (Levine et al. 1985). At the time of diagnosis the majority of patients have locoregional metastasis and approximately 30\% have distant metastatic disease (Jaiyesimi et al. 1992). Because of its rapid propensity to metastasize, IBC is a good paradigm to study the metastatic process in breast cancer.

Initial work on IBC showed that CCN6 messenger RNA is downregulated in a significant number of IBC tumors when compared to stage matched non IBC tumors (van Golen et al. 1999). Our subsequent work 
showed that CCN6 protein is downregulated in invasive carcinomas with lymph node metastasis as well (Huang et al. 2008). Of special note is that the CCN6 gene is located at chromosome 6q21-22, and loss of one copy of the $6 \mathrm{q}$ arm has been shown in 23 to $80 \%$ of human breast cancers, making it one of the most frequent sites for allelic loss in human breast cancer (Chappell et al. 1997; Fujii et al. 1996; Rodriguez et al. 2000). The precise mechanism(s) underlying CCN6's tumor suppressor function has not been entirely elucidated. Our efforts in this direction have shown that CCN6 can regulate tumor growth at least in part through the modulation of IGF-1 signaling pathway, one of the most important growth factors in breast cancer development and progression (Kleer et al. 2004, Zhang et al. 2005). Although we have evidence of CCN6 modulation of IGF-1 signaling in breast epithelial cells, our recent observations suggest that $\mathrm{CCN} 6$ also exerts growth factor independent functions on benign breast epithelial cells. These data and their relevance to human breast cancer progression will be discussed herein.

\section{CCN6 regulates breast cancer growth by interfering with IGF-1 signaling pathway}

Our early laboratory studies uncovered a role for CCN6 in the control of breast tumor growth in IBC and non-IBC tumors. The full-length CCN6 cDNA was sequenced and cloned into an expression vector, and introduced into the IBC cell line SUM149, which exhibit low to absent levels of CCN6 protein (Huang et al. 2008; Kleer et al. 2002). CCN6 transfected cancer cells showed a decreased ability to grow under anchorage independent conditions (Kleer et al. 2002). CCN6 restoration was effective in suppressing in vivo tumor growth in nude mice. CCN6 expression decreased the rate of tumor formation and had a significantly favorable impact in the survival of the mice (Kleer et al. 2002). This work demonstrated that CCN6 has tumor suppressor functions in IBC in vivo and in vitro.

Given the structure of CCN6 protein and its high homology with other members of the $\mathrm{CCN}$ family, we hypothesized that mammary epithelial cells may secrete CCN6 into the extracellular medium where it may regulate insulin like growth factor (IGF) signaling. The IGFs play a central role in breast cancer development (Pollak 2004). Epidemiological and clinical data show that high concentrations of IGF-1 in serum are associated with increased mammographic density (one of the strongest predictors of breast cancer risk), and also reliably predict increased breast cancer risk specifically in premenopausal women (Allen et al. 2005; Byrne et al. 2000; Diorio et al. 2005; Eliassen et al. 2007; Schernhammer et al. 2005). In vitro and in vivo studies have shown that IGFs promote the proliferation, survival, and metastatic ability of breast cancer cells (Diorio et al. 2005; Eliassen et al. 2007). The IGF-1 receptor (IGF-1R) promotes breast cancer growth (Surmacz 2000), metastasis (Carboni et al. 2005; Kim et al. 2007; Sachdev et al. 2004), and its hyperactivation has been linked with increased radioresistance and breast cancer recurrence (Surmacz 2000; Turner et al. 1997).

Studies demonstrated that CCN6 protein is secreted from breast epithelial cells and that once in the extracellular medium is able to decrease the IGF-1-induced activation of the IGF receptor (IGF-1R) and two of its main downstream signaling proteins, IRS- 1 and ERK-1/2, in SUM149 inflammatory breast cancer cells (Kleer et al. 2004). CCN6-rich conditioned media slowed the growth of SUM149 cells. It was also shown that inhibition of CCN6 in HME cells enhances IGF-1 mediated invasion and cell proliferation (Lorenzatti et al. 2011). Taken together, this work uncovered a previously undescribed mechanism of CCN6 function by demonstrating that it is secreted and that it modulates of IGF-IR signaling pathways, cellular growth and invasion of breast cells.

New data from our lab demonstrate that the activation of IGF-1R signaling brought about by CCN6 knockdown is due to induction of IGF-1 levels in the extracellular medium (Lorenzatti et al. 2011). Downregulation of CCN6 in benign mammary epithelial cells under serum starvation increased the levels of $I G F 1$ mRNA as well as the concentration of IGF-1 in the conditioned medium compared with control levels. The levels of IGF-1 protein in the conditioned medium and the induction of IGF-1R and IRS1 phosphorylation by CCN6 knockdown were higher than those exhibited by the highly aggressive breast cancer cell line MDA-MB-231.

It is important to note that $\mathrm{CCN} 3$ (Nov) was also found to modulate the effects on IGF signaling in Ewing's sarcoma cells (Benini et al. 2005). Recently, CCN1 (CTGF) was shown to promote differentiation in rat fibroblasts by enhancing the effects of IGFs (Grotendorst and Duncan 2005). Whether CCN3 or CCN1 exerts an effect on the levels of IGF-1 in the extracellular medium has not been reported.

\section{CCN6 downregulation in non-tumorigenic breast epithelial cells promotes EMT and invasion at least in part through modulation of IGF-1 signaling}

It is recognized that the acquisition of mesenchymal celllike features, hallmark of the process of EMT, contributes to the progression from non-invasive lesions to invasive carcinoma with the ability to metastasize (Hugo et al. 2007). However, very little information is currently avail- 
able regarding the specific mechanisms leading to EMT in the mammary gland. EMT of breast epithelial cells manifests as the development of a stellate and slender morphology and a characteristic protein expression pattern with decreased expression of epithelial markers (e.g. cytokeratin and E-cadherin), and elevated levels of mesenchymal cell markers (e.g. vimentin) (Hugo et al. 2007). Although CCN proteins have been reported to exert a variety of biological functions, it wasn't until recently that CCN6 knockdown was discovered to trigger a phenotypic and gene expression program indicative of EMT.

Experiments using stable knockdown showed that downregulation of CCN6 results in EMT of breast epithelial cells, with upregulation of mesenchymal proteins and down regulation of epithelial proteins (Huang et al. 2008, Zhang et al. 2005). Among these, E-cadherin was consistently suppressed as determined using different experimental methods and cell lines (Huang et al. 2008, Zhang et al. 2005). The association between CCN6 and E-cadherin protein expression in human breast cancer tissues strengthens the relevance of the experimental studies to human breast cancer.

Several transcription factors have been implicated in the repression of E-cadherin including zinc-finger proteins of the Snail/Slug family, $\delta \mathrm{EF} 1 / \mathrm{ZEB} 1$, SIP1, and the basic helix- loop-helix E12/E47 factor (reviewed in (Peinado et al. 2007). Studies have shown that Snail (SNAI1) plays a role in cancer progression, including breast cancer (Peinado et al. 2007). Elevated Snail expression was associated with E-cadherin repression, tumor recurrence, metastasis and poor prognosis in breast cancer (Moody et al. 2005; Peinado et al. 2007).

The transcriptional regulator ZEB1, by binding to the E-boxes of the E-cadherin gene proximal promoter, has been shown to down-regulate E-cadherin, and to induce EMT in breast and other cancer cells including colorectal and prostatic adenocarcinomas (Aigner et al. 2007; Eger et al. 2005; Schmalhofer et al. 2009; Spaderna et al. 2008). The molecular events that lead to ZEB1 overexpression have not been fully elucidated, but recent studies implicate extracellular signaling factors including TGF $\beta, T N F \alpha$, IGF-1, as well as COX-2, EGF receptor (EGFR) and estrogen receptor activation (Graham et al. 2008; Schmalhofer et al. 2009). Interestingly, recent work has shown that the miR-200 family of micro-RNAs is associated with down-regulation of ZEB1 and maintenance of the epithelial phenotype in the breast (Bracken et al. 2008; Burk et al. 2008; Korpal et al. 2008; Park et al. 2008; Shirakihara et al. 2007).

Given this, a major focus of our research has been devoted to elucidating the molecular basis of CCN6-

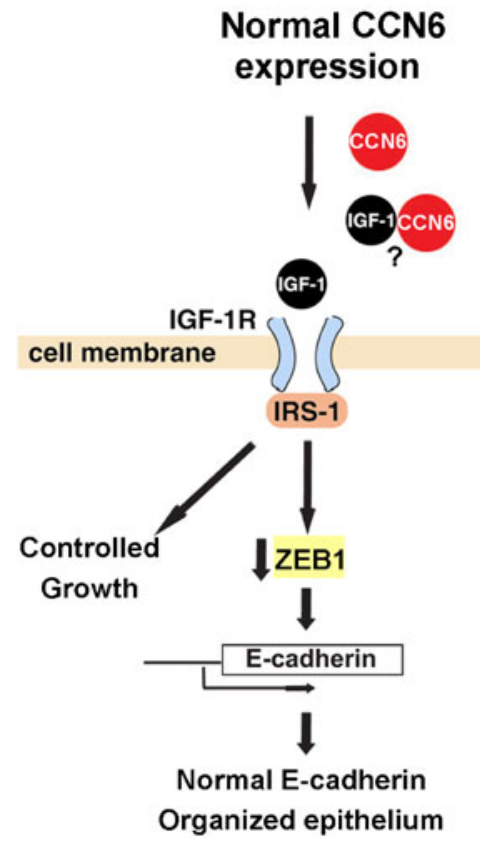

Fig. 1 Working model for CCN6 function in mammary epithelial cells and breast cancer cells. On the basis of our data, we propose that CCN6 protein contributes to the maintenance of normal breast homeostasis. Reduction of CCN6 protein levels, as it occurs in breast carcinomas with metastatic propensity, increases IGF-1 levels in the extracellular medium and results in activation of IGF-1R signaling with resulting ZEB1dependent EMT and invasion, as well as cellular growth. CCN6 reduction

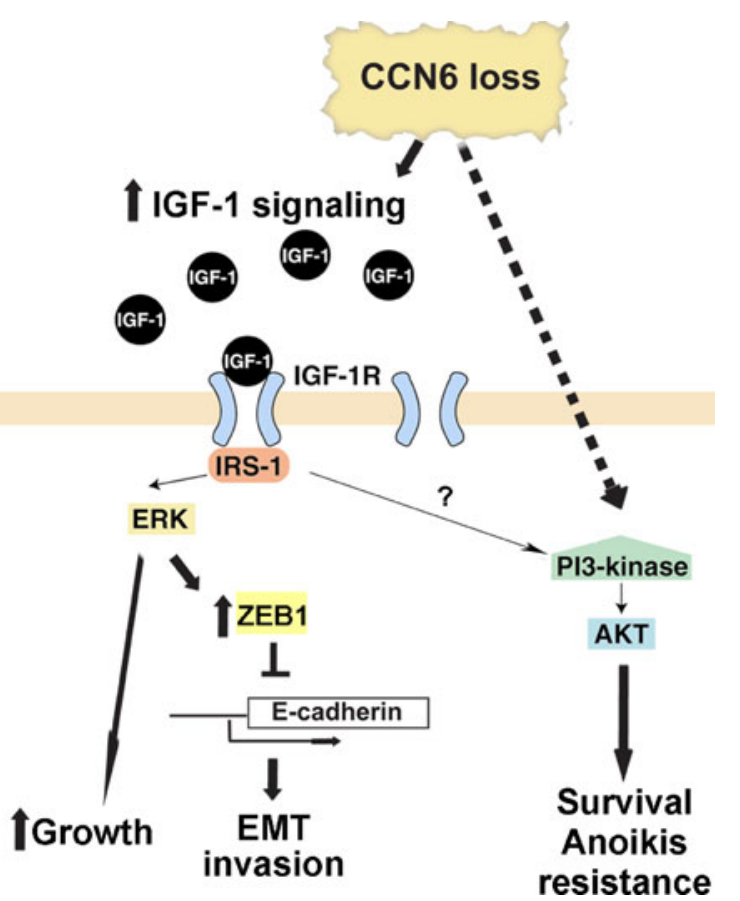

can promote a growth factor independent survival program with anoikis resistance, which depends on activation of PI3K/Akt-1 proteins, and that can be rescued by exogenous recombinant CCN6 protein. Whether CCN6 binds to IGF-1 in the extracellular medium, remains to be proven. Based on our data, the identification of means to restore CCN6 expression in the mammary epithelium may serve as a therapeutic target against breast cancer growth and invasion 
mediated EMT in the mammary epithelium. Our laboratory recently reported that downregulation of $\mathrm{CCN} 6$ induces EMT and decreases E-cadherin expression in the breast epithelium by increasing the levels of Snail and ZEB1 messenger RNA and proteins (Huang et al. 2008). Upon CCN6 knockdown in human mammary epithelial cells, ZEB1 and Snai1 proteins are up-regulated and recruited to the proximal E-cadherin promoter (Huang et al. 2008). Binding of Snail or ZEB1 to the promoter of the Ecadherin gene is necessary for CCN6's effect on E-cadherin expression (Huang et al. 2008).

These data opened the question as to whether CCN6 regulates transcription of ZEB1 through modulation of IGF1 signaling pathway. Experiments using non tumorigenic breast epithelial cells with CCN6 knockdown revealed that addition of exogenous recombinant human CCN6 protein blunts IGF-1 pathway activation and leads to a reduction of ZEB1 expression. Functionally, exogenous CCN6 protein induces an epithelial phenotype and blocks invasion in CCN6 knockdown human mammary epithelial cells (HME) compared to controls. Mechanistic studies utilizing gainand loss- of function approaches demonstrate that the effect of CCN6 on ZEB1 is dependent on IGF-1 pathway integrity (Lorenzatti et al. 2011).

\section{CCN6 regulates survival of non-tumorigenic breast epithelial cells independent of exogenous growth factors}

A fundamental difference between normal and cancer cells is their requirement for extracellular signals (Hanahan and Weinberg 2000). While normal cells die upon deprivation of extracellular growth factors, cancer cells have the ability to survive in their absence (Hanahan and Weinberg 2000). We observed that CCN6 knockdown was sufficient to increase survival of mammary epithelial cells in serum free conditions. This prompted us to investigate the underlying mechanisms. Our studies showed that CCN6 blockade confers a distinct survival advantage to nontumorigenic breast epithelial cells, MCF10A and HME (Huang et al. 2010). CCN6 downregulation leads to growth factor-independent survival and proliferation, and is sufficient to trigger anchorage-independent growth of mammary epithelial cells (Huang et al. 2010).

Anoikis, or detachment-induced apoptosis, is a protective mechanism by which epithelial cells die upon loosing contact with the extracellular matrix. The acquisition of anoikis resistance has been shown to promote breast cancer progression and metastasis by enabling cancer cells to survive in the vascular or lymphatic channels (Douma et al. 2004; Moro et al. 2009). We have found that CCN6 is a novel regulator of anoikis in breast cancer cells. $\mathrm{CCN} 6$ knockdown in MCF10A and HME cells is sufficient to prevent anoikis and promote growth under anchorage independent conditions in the absence of exogenous growth factors (Huang et al. 2010). Mechanistically, the growth factor-independent survival and anoikis resistance conferred by CCN6 knockdown require activation of the PI3K/Akt-1 signaling pathway (Huang et al. 2010). We postulate that the induction of anoikis resistance may contribute to the enhanced metastases observed in invasive carcinomas with low CCN6 protein expression (van Golen et al. 1999), (Huang et al. 2008).

\section{Closing remarks}

Of the CCN family, CCN6 (WISP3) is the least studied member. Since the discovery that CCN6 expression is reduced in a large number of invasive carcinomas of the breast, we have devoted our efforts to elucidating its possible role as a tumor suppressor. Figure 1 illustrates our working model for CCN6 function in breast tumorigenesis. Our data support the hypothesis that CCN6 maintains controlled growth and an epithelial phenotype in the breast. Reduction of CCN6 expression results in increased levels of IGF-1 and activity of IGF-1R signaling pathway in mammary epithelial cells. This in turn is responsible for ZEB1-mediated EMT and invasion, as well as enhanced cell growth. Another consequence of $\mathrm{CCN} 6$ protein reduction in nontumorigenic breast epithelial cells is the activation of a growth factor independent survival program with anoikis resistance, which can be overcome by exogenous CCN6 protein. Studies aimed at pinpointing the molecular mechanism by which CCN6 regulates these processes is an area of important forthcoming research. Another area of investigation is on the possible relationship between CCN6 and other $\mathrm{CCN}$ family members with functions in breast tumorigenesis, especially $\mathrm{CCN} 1$ and $\mathrm{CCN} 2$, which is currently unknown. The roles of CCN6 in the regulation of breast cancer cell survival, EMT and invasion has potential therapeutic implications.

Acknowledgements We thank members of the Kleer laboratory for critical discussions.

Open Access This article is distributed under the terms of the Creative Commons Attribution Noncommercial License which permits any noncommercial use, distribution, and reproduction in any medium, provided the original author(s) and source are credited.

\section{References}

Aigner K, Dampier B, Descovich L, Mikula M, Sultan A, Schreiber M et al (2007) The transcription factor ZEB1 (deltaEF1) promotes tumour cell dedifferentiation by repressing master regulators of epithelial polarity. Oncogene 26:6979-6988 
Allen NE, Roddam AW, Allen DS, Fentiman IS, Dos Santos SI, Peto J et al (2005) A prospective study of serum insulin-like growth factor-I (IGF-I), IGF-II, IGF-binding protein-3 and breast cancer risk. Br J Cancer 92:1283-1287

Benini S, Perbal B, Zambelli D, Colombo MP, Manara MC, Serra M et al (2005) In Ewing's sarcoma CCN3(NOV) inhibits proliferation while promoting migration and invasion of the same cell type. Oncogene 24:4349-4361

Bracken CP, Gregory PA, Kolesnikoff N, Bert AG, Wang J, Shannon MF et al (2008) A double-negative feedback loop between ZEB1-SIP1 and the microRNA-200 family regulates epithelialmesenchymal transition. Cancer Res 68:7846-7854

Burk U, Schubert J, Wellner U, Schmalhofer O, Vincan E, Spaderna S et al (2008) A reciprocal repression between ZEB1 and members of the miR-200 family promotes EMT and invasion in cancer cells. EMBO Rep 9:582-589

Byrne C, Colditz GA, Willett WC, Speizer FE, Pollak M, Hankinson SE (2000) Plasma insulin-like growth factor (IGF) I, IGF-binding protein 3, and mammographic density. Cancer Res 60:3744-3748

Carboni JM, Lee AV, Hadsell DL, Rowley BR, Lee FY, Bol DK et al (2005) Tumor development by transgenic expression of a constitutively active insulin-like growth factor I receptor. Cancer Res 65:3781-3787

Chappell SA, Walsh T, Walker RA, Shaw JA (1997) Loss of heterozygosity at chromosome $6 \mathrm{q}$ in preinvasive and early invasive breast carcinomas. Br J Cancer 75:1324-1329

Dawood S, Cristofanilli M (2007) What progress have we made in managing inflammatory breast cancer? Oncology (Williston Park) 21:673-679, discussion 679-680, 686-677

Diorio C, Pollak M, Byrne C, Masse B, Hebert-Croteau N, Yaffe M et al (2005) Insulin-like growth factor-I, IGF-binding protein-3, and mammographic breast density. Cancer Epidemiol Biomarkers Prev 14:1065-1073

Douma S, Van Laar T, Zevenhoven J, Meuwissen R, Van Garderen E, Peeper DS (2004) Suppression of anoikis and induction of metastasis by the neurotrophic receptor TrkB. Nature 430:10341039

Eger A, Aigner K, Sonderegger S, Dampier B, Oehler S, Schreiber M et al (2005) DeltaEF1 is a transcriptional repressor of E-cadherin and regulates epithelial plasticity in breast cancer cells. Oncogene 24:2375-2385

Eliassen AH, Tworoger SS, Mantzoros CS, Pollak MN, Hankinson SE (2007) Circulating insulin and c-peptide levels and risk of breast cancer among predominately premenopausal women. Cancer Epidemiol Biomarkers Prev 16:161-164

Fujii H, Zhou W, Gabrielson E (1996) Detection of frequent allelic loss of 6q23-q25.2 in microdissected human breast cancer tissues. Genes Chromosomes Cancer 16:35-39

Graham TR, Zhau HE, Odero-Marah VA, Osunkoya AO, Kimbro KS, Tighiouart $\mathrm{M}$ et al (2008) Insulin-like growth factor-I-dependent up-regulation of ZEB1 drives epithelial-to-mesenchymal transition in human prostate cancer cells. Cancer Res 68:2479-2488

Grotendorst GR, Duncan MR (2005) Individual domains of connective tissue growth factor regulate fibroblast proliferation and myofibroblast differentiation. FASEB J 19:729-738

Hanahan D, Weinberg RA (2000) The hallmarks of cancer. Cell 100:57-70

Huang W, Zhang Y, Varambally S, Chinnaiyan AM, Banerjee M, Merajver SD et al (2008) Inhibition of CCN6 (Wnt-1-induced signaling protein 3 ) down-regulates E-cadherin in the breast epithelium through induction of snail and ZEB1. Am J Pathol 172:893-904

Huang W, Gonzalez ME, Toy KA, Banerjee M, Kleer CG (2010) Blockade of CCN6 (WISP3) activates growth factor-independent survival and resistance to anoikis in human mammary epithelial cells. Cancer Res 70:3340-3350
Hugo H, Ackland ML, Blick T, Lawrence MG, Clements JA, Williams ED et al (2007) Epithelial-mesenchymal and mesenchymalepithelial transitions in carcinoma progression. J Cell Physiol 213:374-383

Jaiyesimi IA, Buzdar AU, Hortobagyi G (1992) Inflammatory breast cancer: a review. J Clin Oncol 10:1014-1024

Kim HJ, Litzenburger BC, Cui X, Delgado DA, Grabiner BC, Lin X et al (2007) Constitutively active type I insulin-like growth factor receptor causes transformation and xenograft growth of immortalized mammary epithelial cells and is accompanied by an epithelial-to-mesenchymal transition mediated by NF-kappaB and snail. Mol Cell Biol 27:3165-3175

Kleer CG, Zhang Y, Pan Q, van Golen KL, Wu ZF, Livant D et al (2002) WISP3 is a novel tumor suppressor gene of inflammatory breast cancer. Oncogene 21:3172-3180

Kleer CG, Zhang Y, Pan Q, Merajver SD (2004) WISP3 (CCN6) is a secreted tumor-suppressor protein that modulates IGF signaling in inflammatory breast cancer. Neoplasia 6:179-185

Korpal M, Lee ES, Hu G, Kang Y (2008) The miR-200 family inhibits epithelial-mesenchymal transition and cancer cell migration by direct targeting of E-cadherin transcriptional repressors ZEB1 and ZEB2. J Biol Chem 283:14910-14914

Levine PH, Steinhorn SC, Ries LG, Aron JL (1985) Inflammatory breast cancer: the experience of the surveillance, epidemiology, and end results (SEER) program. J Natl Cancer Inst 74:291-297

Lorenzatti G, Huang W, Pal A, Cabanillas AM, Kleer CG (2011) CCN6 (WISP3) decreases ZEB1-mediated EMT and invasion by attenuation of IGF-1 receptor signaling in breast cancer. J Cell Sci 124:1752-1758

Moody SE, Perez D, Pan TC, Sarkisian CJ, Portocarrero CP, Sterner CJ et al (2005) The transcriptional repressor Snail promotes mammary tumor recurrence. Cancer Cell 8:197-209

Moro L, Arbini AA, Yao JL, di Sant'Agnese PA, Marra E, Greco M (2009) Mitochondrial DNA depletion in prostate epithelial cells promotes anoikis resistance and invasion through activation of PI3K/Akt2. Cell Death Differ 16:571-583

Park SM, Gaur AB, Lengyel E, Peter ME (2008) The miR-200 family determines the epithelial phenotype of cancer cells by targeting the E-cadherin repressors ZEB1 and ZEB2. Genes Dev 22:894907

Peinado H, Olmeda D, Cano A (2007) Snail, Zeb and bHLH factors in tumour progression: an alliance against the epithelial phenotype? Nat Rev Cancer 7:415-428

Pollak MN (2004) Insulin-like growth factors and neoplasia. Novartis Found Symp 262:84-98, discussion 98-107, 265-108

Rodriguez C, Causse A, Ursule E, Theillet C (2000) At least five regions of imbalance on $6 \mathrm{q}$ in breast tumors, combining losses and gains. Genes Chromosomes Cancer 27:76-84

Sachdev D, Hartell JS, Lee AV, Zhang X, Yee D (2004) A dominant negative type I insulin-like growth factor receptor inhibits metastasis of human cancer cells. J Biol Chem 279:5017-5024

Schernhammer ES, Holly JM, Pollak MN, Hankinson SE (2005) Circulating levels of insulin-like growth factors, their binding proteins, and breast cancer risk. Cancer Epidemiol Biomarkers Prev 14:699-704

Schmalhofer O, Brabletz S, Brabletz T (2009) E-cadherin, beta-catenin, and ZEB1 in malignant progression of cancer. Cancer Metastasis Rev 28:151-166

Shirakihara T, Saitoh M, Miyazono K (2007) Differential regulation of epithelial and mesenchymal markers by deltaEF1 proteins in epithelial mesenchymal transition induced by TGF-beta. Mol Biol Cell 18:3533-3544

Spaderna S, Schmalhofer O, Wahlbuhl M, Dimmler A, Bauer K, Sultan A et al (2008) The transcriptional repressor ZEB1 promotes metastasis and loss of cell polarity in cancer. Cancer Res 68:537-544 
Surmacz E (2000) Function of the IGF-I receptor in breast cancer. J Mammary Gland Biol Neoplasia 5:95-105

Turner BC, Haffty BG, Narayanan L, Yuan J, Havre PA, Gumbs AA et al (1997) Insulin-like growth factor-I receptor overexpression mediates cellular radioresistance and local breast cancer recurrence after lumpectomy and radiation. Cancer Res 57:3079-3083

van Golen KL, Davies S, Wu ZF, Wang Y, Bucana CD, Root H et al (1999) A novel putative low-affinity insulin-like growth factorbinding protein, LIBC (lost in inflammatory breast cancer), and
RhoC GTPase correlate with the inflammatory breast cancer phenotype. Clin Cancer Res 5:2511-2519

Ventura AC, Merajver SD (2008) Genetic determinants of aggressive breast cancer. Annu Rev Med 59:199-212

Zhang Y, Pan Q, Zhong H, Merajver SD, Kleer CG (2005) Inhibition of CCN6 (WISP3) expression promotes neoplastic progression and enhances the effects of insulin-like growth factor-1 on breast epithelial cells. Breast Cancer Research 7: R1080-R1089 